\title{
The Impact of Virtual Reality Technology on the Protection of Traditional Ancestral Temple Architecture in Eastern Hubei Province
}

\author{
Jiahao Yin ${ }^{1} \mathrm{Kai} \mathrm{Cao}^{1, *}$ \\ ${ }^{1}$ College of Art and Design, Wuhan Textile University, Wuhan, Hubei 430073, China \\ "Corresponding author. Email: 1064380174@qq.com
}

\begin{abstract}
Ancestral temple is a model of Chinese architectural art. Due to its unique geographical environment, the traditional ancestral temples in Eastern Hubei retain a large number of exquisite architectural structures, and also record the precious vernacular immigrant culture. How to solve the problem of protecting ancestral temple architecture in the contemporary society is urgent. The emergence of virtual reality (Virtual Reality, referred to as VR) technology and its application in multiple fields provide us with new protection ideas. This article first sorts out the current status of the ancestral temples in the eastern Hubei, summarizes two key points for the protection of the traditional ancestral temples in Eastern Hubei combining with the historical reasons, analyzes the application cases of VR technology in the protection of traditional buildings, summarizes the impact of VR technology on the protection of traditional buildings, and finally puts forward the experience mode of the architectural culture of the ancestral temple in Eastern Hubei with the support of VR technology.
\end{abstract}

Keywords: virtual reality, traditional architecture, ancestral temple, building protection

\section{INTRODUCTION}

China's folk ancestral temple architecture is a typical representative of the traditional architectural art, and also records the public culture of Chinese native blood relationships. Ancestral temple is also called the family temple. Ancient officials all have temples, and the ordinary people sacrifice in the bedroom. After that, they gathered the phrator and established temple to worship their ancestors. The prosperity of Chinese folk ancestral temples is closely related to the traditional Confucian culture and clan concept. With the change of society, the negative function of ancestral temple has been weakened. These traditional buildings of ancestral temple have now become exquisite specimens of folk architecture art and folk crafts. Due to the change of function and the change of local public cultural center in Eastern Hubei, the survival of ancestral temples in Eastern Hubei, as well as most traditional buildings of ancestral temples, in the contemporary society has become an urgent social problem. In recent years, the protection of traditional cultural buildings has become a hot topic of discussion, and the dimension of the discussion is also deepening. The combination with new technology further promotes the development of related research. Virtual reality (VR) technology is also a brilliant application in the field of traditional architectural protection due to its remarkable features of immersion, interactivity and imagination. The application of VR technology in the protection of traditional ancestral temple is a problem worthy of further study.

\section{CURRENT SITUATION OF ANCESTRAL TEMPLES IN EASTERN HUBEI PROVINCE}

The eastern Hubei Province was located in the area of Chu dynasty and Wu dynasty in ancient times. Now, it is located in the middle reaches of the Yangtze River and the junction of Hubei, Henan, Anhui and Jiangxi provinces. The terrain is mostly hills and basins. In Ming and Qing Dynasties, it was also a distributing center for immigrants. Both traditional residential buildings and ancestral temples in this area are not only of strong Chu style, but also have the characteristics of northern Jiangxi and southern Anhui. In the past, most of the people here lived together and attached great importance to the construction of ancestral temples. Therefore, these traditional ancestral temples in Eastern Hubei are not only full of the research value of traditional crafts and historical culture, but also valuable historical materials for the study of surname culture, population migration and local customs.

The villages in Eastern Hubei are typical Chinese traditional consanguineous villages, with strong clan concept and traditional family culture. Ancestral temple 
is often the core of the village, and the planning pattern of the whole village starts from ancestral temple. According to the relationship between ancestral temple buildings and residential buildings, there are two main types of ancestral temples in Eastern Hubei: one is the independent main ancestral temple, which has a large scale and is basically a courtyard with three entrances or more, and most of them are the main ancestral temples of one clan, so the name plate is often raised by surname, such as "Wu ancestral temple", "Jiao ancestral temple"; the other is the mixed ancestral temple, which is usually associated with schools and residential buildings and of moderate scale, such as the ancestral temple of pailou village in Tongshan. And a small part of the ancestral temple is directly selected from the house as the ancestral temple.

These ancestral temples are not only flexible in architectural form, but also exquisite in interior decoration. Influenced by the architectural style of the Hui school, the architectural appearance of the ancestral temples in Eastern Hubei mostly includes the memorial archway, the rolling dragon ridge, horse head and cloud wall and other elements, such as Wu's ancestral temple in Hong'an, Liang's ancestral temple in Yangxin, etc. In terms of architectural decoration, the sculpture technology has been brought to the extreme. For example, in front of the steps of Liang's ancestral temple, the auspicious animals such as kylin and sika deer have been carved with white marble. In the stage skirt of the Guanle building of Wu's ancestral temple, there is a 9-meter-long exquisite wood carving, which depicts the river view of Sanzhenjiang in Wuhan, and lifelike. With a large number of human and capital investment, this splendid ancestral temple building was established. However, with the development of society, some feudal thoughts behind the ancestral temple are gradually hated by people. A large number of ancestral temples are destroyed, or transformed for other uses. Nowadays, the traditional ancestral temple can only survive in the contemporary society only by removing its dross and absorbing its essence. The primitive nature of these exquisite ancestral temple buildings and the historical culture behind them are gradually losing. People do not want to return to the original social environment. However, it is necessary to have a sense of historical responsibility to protect these local customs.

\section{THE KEY TO PROTECT THE ANCESTRAL TEMPLE BUILDING IN EASTERN HUBEI Province}

\section{A. Reinterpretation of historical value}

The cultural significance of traditional architecture comes from people's cognition of the value of historical time, which is closely connected with the social composition, class distribution, social consciousness, customs and habits in different historical periods. With the flow of time, the past value of traditional architecture and contemporary social civilization gradually separated or even contradicted. However, as a natural element of social structure, the function and connotation of architecture will change with the change of creative environment. The prosperity of ancestral temple architecture is closely related to the clan concept and some feudal thoughts at that time, some of which have deviated from the civilization of contemporary society. In the protection of traditional ancestral temple buildings, it is necessary to start from the contemporary social civilization, excavate its current value of the times, so as to reinterpret the historical value. The historical value of traditional architecture is gradually accumulated in the long river of time. To find a new value of times is also an active input to the historical value of traditional architecture itself.

\section{B. Continuation and renewal of functions}

The decline of traditional architecture is largely due to the decline of function. The reasonable continuation and renewal of function is the key point for the successful integration of traditional architecture and contemporary society. In order to protect the traditional ancestral temple buildings better, it is required to make its function match with the needs of contemporary society. On the one hand, through repair and transformation, the function and use value of physical space should be improved; on the other hand, the degree of public participation should be strengthened. The function of the building is ultimately reflected in the interaction with the users. The extensive participation of the public will greatly avoid the discomfort of function update, so that the changed function will be more lasting. It is necessary to combine the social order of the village, the demand of the public space and the cultural custom when the function of the ancestral temple building in Eastern Hubei is continued and renewed so as to integrate it into the contemporary society better.

\section{APPLICATION OF VR TECHNOLOGY IN THE PROTECTION OF TRADITIONAL BUILDINGS}

VR technology is to create an interactive virtual environment by simulating the real environment with a computer simulation system. With the help of helmets or glasses and other tools, people can immerse in the virtual environment and obtain new space perception experience. After the "first year of VR" in 2016, VR technology gradually came into the public's view. Google, HTC, Tencent and Alibaba began to develop VR industry, and VR experience has become a hot topic. The combination of VR technology and other industries is also becoming more frequent, such as "VR Games", "VR education", "VR film and television" and 
so on. With the growing maturity of VR technology, the application of VR + traditional building protection is also beginning to try.

The "digital Dunhuang" project, jointly carried out by the Institute of computer science of the Chinese Academy of Sciences, Wuhan University and Zhejiang University, is to collect sculptures, murals and geomorphic environment in the Mogao Grottoes through detail shooting and laser scanning, and then combine these images and three-dimensional data with VR technology to restore the real features of the Mogao Grottoes, so that people around the world can use VR auxiliary tools, and enjoy the delicacy of Mogao Grottoes at close range. In 2017, invited by Shanghai architectural heritage protection and restoration Expo, Yunwu technology displayed VR video of historic restoration of five major palaces (The Old Summer Palace, Daming Palace, E-Pang Palace, Weiyang Palace and Mount Li Palace) and received a lot of praise from visitors. Many traditional buildings are limited by space and time, so it is impossible to realize convenient visit. The emergence of VR technology just breaks this limitation, so that visitors can fully appreciate these traditional buildings anytime and anywhere. At the same time, it avoids too much direct contact, which also provides protection for the traditional buildings themselves.

\section{CHANGES OF TRADITIONAL BUILDING PROTECTION METHODS UNDER THE INFLUENCE OF VR TECHNOLOGY}

\section{A. Carrier change: from two-dimensional to three- dimensional immersion}

From oracle-bone tripod to bamboo slips and wooden slips, from silk paper to tape, and to the recent electronic data and optical storage, the media people use to record things are changing with the progress of science and technology. Its technical support has also gradually changed from a tangible carrier to an intangible carrier from the initial natural form to the initial processing of original materials to electronic technology. In the past, the records of traditional architectural information were mainly based on local records, historical records and other paper carriers. With the introduction of image technology, audiovisual carrier was built together with acoustics and optics. Now, VR technology adds immersive experience on the basis of the audio-visual carrier to form an interactive virtual simulation carrier, which completely pushes the recording carrier from twodimensional plane to three-dimensional immersion. This multi-sensory information media will better enhance people's experience of traditional architecture, and mobilize people's interest in exploring traditional architecture to the greatest extent.

\section{B. The change of content: from oneness to pluralism}

The change of recording carrier also drives the diversification of recording content. At the beginning, when relying on paper and other carriers, the recordable contents of traditional architecture were limited to the words and paintings of the recorder, while image carriers gradually recorded the real style of the architecture. The recording contents of both of them were still based on the building itself, which had certain limitation of time. VR technology has created a virtual immersion environment that is very similar to the real space, and has reserved the space that can be created independently. Therefore, the recorded content can not only restore the current style of the building, but also restore its historical style in different periods, and even present its future development and changes. In addition, VR technology can also add recording content, so that visitors can learn all the information related to the traditional building faster and more deeply.

\section{The change of communication form: from unilateral output to group participation}

The change of media makes the ways and forms of communication more abundant. With the initiative of everyone reading the original literature, people can understand the content of traditional architectural culture. With the emergence of electronic media, some exquisite images integrate with other modern content, and a few people pay attention to the traditional architectural culture. However, these modes of communication are still independent of the environment. The understanding of traditional architectural culture is slow and the reception is not deep, which belongs to passive unilateral output. The interactive features brought by VR technology can combine traditional architecture with other more interesting fields, such as VR + traditional architecture + games, so that the experiencer can start to actively understand the traditional architectural culture, and make appropriate interactive presupposition in advance, which improves the degree of public participation and provides a more reliable practical basis for some changes in architectural protection later.

\section{EXPERIENCE MODE OF ANCESTRAL TEMPLE ARCHITECTURE CULTURE IN EASTERN HUBEI PROVINCE WITH THE SUPPORT OF VR TECHNOLOGY}

\section{A. The experience logic of the ancestral temple building architecture in Eastern Hubei Province with the support of VR technology}

Through the application of VR technology in various fields, combining with the communication way of traditional architectural culture in the past, the VR experience logic of the ancestral temple architectural 
culture in Eastern Hubei can be divided into three stages. The first step is "beginning". In this stage, the experiencer enters into the virtual traditional architectural environment in advance through auxiliary equipment, and incarnates as a part of the traditional architectural environment through the initial contact to understand the past and the story behind the traditional building. The second is "exploration". After the initial impression, the experimenter is more skilled in the control of their sensory interaction. At this time, they can start to capture all kinds of detail signals by themselves and learn more about the traditional building with their own judgment. The third is "aftertaste". After the exploration, the experimenter's sensory go back to the real world, but the real immersion experience will make the whole exploration process as if it happened, and then have a deep impression on the traditional building, thus completing the whole process of sightseeing buildings.

\section{B. Immersive experience mode}

One of the core characteristics of VR technology is immersion, which is a subjective perception of virtual environment. VR technology extends the senses of the experiencer into the virtual environment, and the experiencer's sensory system will respond to sensory feedback in the virtual environment in the same way that it would in the real world. The immersion feeling under the experience mode can be realized in three steps. First, it attracts the public to participate in the virtual experience of traditional buildings with new technology. Second, it makes the experiencer incarnate as a part of the virtual environment to create a preliminary sense of substitution. Finally, through guided exploration, the experiencer will further invest in the virtual tour of traditional buildings, and achieve an all-round immersive experience with plots and multi-sensory feedback.

\section{Interactive experience mode}

Just like the process of getting familiar with each other, the deep understanding of traditional architecture also needs people to communicate with architecture. VR technology is loaded with various sensing technologies, which can preset various reaction actions and add new guiding roles. For example, it can create historical figures related to the building, so that the experiencer can have some conversations or actions with the characters. Also, it can restore a previous use scene of the building, so that the experiencer can truly feel a fresh building. To some extent, this mode changes the relationship between the subject and the object in the process of tour, and provides different interactive choices for the experiencer, which makes the experiencer no longer watch passively when visiting the traditional buildings, but touch and interact truly.

\section{CONCLUSION}

"VR + traditional ancestral temple building" is a transformation of the communication mode of traditional architectural culture, which promotes the promotion of traditional architectural culture and is of important practical significance for the inheritance of traditional architectural technology. Because of its unique historical position and geographical environment, the ancestral temple in Eastern Hubei not only has a high value of architectural art, but also records unique culture of local immigrants. From the layout of construction to the interior sculpture decoration, it shows a high level of technology and aesthetic level, and is a cultural product of the perfect combination of technology and art. Using the characteristics of immersion and interaction of VR technology can not only solve the embarrassing situation in contemporary society, but also enhance the public's interest in traditional ancestral temple architecture, making the traditional architectural culture better understood by the public, and really promoting the protection process of traditional architecture.

\section{References}

[1] Yao Meikang, Wu Yao. Virtual Simulation in the Protection of Architectural Heritage: Research and Practice [J]. Research on Heritages and Preservation, 2018, 3 (05): 66-70. (in Chinese)

[2] Tan Gangyi, Ren Danni. The Form and Its Social Origins of Ancestral Worshipping Space - An Elaboration on Big Houses with Ancestral Temples in Eastern Hubei Province [J]. Architectural Journal, 2015 (02): 97-101. (in Chinese)

[3] $\mathrm{Hu}$ Shaozong. The Form and Connotation of Traditional Ancestral Temple's Building Space: Take Ke Village's Ancestral Temple in Qingshan of Eastern Hubei as an Example [J]. Art \& Design, 2014 (10): 125-126. (in Chinese)

[4] Xin Yifeng. Wu Temple, NO.1 Ancestral Temple In East of Hubei [J]. Interior Design Construction, 2011 (12): 118-121. (in Chinese)

[5] Li Baihao, Yang Jie. Functions, Forms and Culture of Hubei Vernacular Architecture [J]. Huazhong Architecture, 2007 (1): 176-179. (in Chinese)

[6] Yao Meikang, Wu Yao, Virtual Simulation in the Protection of Architectural Heritage: Research and Practice [J]. Research on Heritages and Preservation, 2018, 3(05): 66-70. (in Chinese)

[7] Wang Dongbo, Ancient Architecture in the Virtual Scene and Spacial Experience [D]. Hunan University, 2017. (in Chinese) 